\title{
THE PROCESS OF REGENERATIVE HEAT TREATMENT OF THE VALVE CHAMBER OF THE STEAM TURBINE
}

\author{
Agata Wieczorska \\ Gdynia Maritime University, Faculty of Marine Engineering \\ Morska Street 81-87, 81-225 Gdynia, Poland \\ tel.: +4858 5586564, fax: +48585586399 \\ e-mail:a.wieczorska@wm.umg.edu.pl
}

\begin{abstract}
Steel castings are often used in the construction of valve chambers of steam turbines. Stringent requirements are set due to the continuous operation of the material at elevated temperatures, in the order of $300^{\circ} \mathrm{C}$ to $600^{\circ} \mathrm{C}$. The material of the valve chamber must be resistant to fatigue-creep changes as well as corrosion. This material must be also resistant to dynamic damage which occures when the turbine is starting and stopping. Dynamic damage is induced by a short-lasting but intense accumulation of localized stresses. The castings of the valve chambers of the steam turbine are usually made from the "three-component" type CrMoV-cast steel. Mentioned castings of the valve chamber are continuously subjected to high temperatures, either constant and periodically variable stresses. Due to this, the degradation process of material of the castings is taking place. It is caused by physicochemical processes such as: creep, relaxation, thermal fatigue, corrosion, erosion and changes in material properties, e.g. displacement of the critical point of brittleness. Finally, first cracks and deformations can be observed in the material during the operation. The art presents the process of revitalization technology of the steam turbine valve chamber which was subjected to long-term operation at high temperatures. The revitalization process is aimed at improving the plastic properties of the material and, as the result, extending its service life. The research presented in the article show that impact strength of the chamber material after revitalization is very high. Also the strength properties of the valve chamber, after revitalization, are high and in line with the requirements. The study show that the revitalization of the valve chamber was carried out correctly and restored the material to plastic deformation.
\end{abstract}

Keywords: regenerative heat treatment, valve chamber, steam turbine

\section{Introduction to the issue of revitalization}

The most important stage of the revitalization process is high-temperature heat treatment, aimed at reversing the brittleness and improving the technological implementation of repairs with welding. This treatment is aimed at heating the chamber in the furnace to the austenitizing temperature, and then applying cooling that guarantees the formation of a bainitic structure. After such a heat treatment, the place where there was a ferrite with $70 \%$ of the pearlite content creates a bainitic structure with highly tempered martensite. The carbides on the boundaries and inside the grains are fine and they are evenly distributed. Low-carbon borders are disappearing. However, micro fatigue-fatigue weaknesses are still present in weak intensity mainly from non-metallic inclusions. As a result of the high-temperature treatment of carbides, they reinforce the structure's cohesion $[1,4,5]$.

The revitalization process is a set of treatments consisting of:

- comprehensive assessment of the technical condition of the valve chamber based on:

- defectoscopic tests (100\% of internal and external surfaces) after sanding or shot blasting (visual and magnetic-powder tests),

- destructive material tests (microstructure, hardness, impact resistance, etc.),

- geometry measurements,

- calculations of the degree of exhaustion of durability,

- removal of surface cracks and padding of cavities using a weld metal with a composition 
similar to the cast material,

- heat treatment of the chamber in the furnace in order to:

- removal of welding stresses,

- removing post-mining stresses,

- correcting the geometry,

- regeneration of the structure to a degree that allows the improvement of artistic properties,

- machining of all planes and grooves requiring legalization,

- thread regeneration $[1,4,6]$.

\section{The research methodology}

The valve chamber of the steam power turbine is an element exposed to variable heat and mechanical loads during operation. Due to long operating periods (over 100,000 operating hours) cracks frequently appear on the surface of the chamber and shape deformation takes place. A valve chamber was handed over to the revitalization and it underwent 232658 hours for the current renovation. The chemical composition of the tested G21CrMoV4-6 cast steel (L21HMF) is shown in Tab. 1.

Tab. 1. Chemical composition of cast steel of the L21HMF

\begin{tabular}{|c|c|c|c|c|c|}
\hline Type of material & $\mathrm{C}$ & $\mathrm{Si}$ & $\mathrm{Mn}$ & $\mathrm{P} \max$ & $\mathrm{S} \max$ \\
\hline L21HMF G21CrMoV4-6 & $0.18-0.25$ & $0.20-0.50$ & $0.40-0.70$ & 0.030 & 0.030 \\
\hline Standard & $\mathrm{Cr}$ & $\mathrm{Mo}$ & $\mathrm{Ni}$ & $\mathrm{Cu}$ & $\mathrm{V}$ \\
\hline PN-89/H-83157 & $0.90-1.20$ & $0.50-0.70$ & $\leq 0.30$ & $\leq 0.30$ & $0.20-0.35$ \\
\hline
\end{tabular}

After cleaning the valve chamber by sanding, surface tests were first made using the magneticpowder method on $100 \%$ of the cast surface.

The 16 cracks were detected on the outer surface of the chamber, whereas 3 cracks on the inner surface. All the cracks detected were qualified for removal by milling, the rebate locations were reexamined by the magnetic-powder method to verify the correctness of this operation, because all defects had to be removed to healthy material. The resulting milling results were qualified for repair by welding, which will be carried out only later in the revitalization process. An example of detected discontinuities is shown in Fig. 1 [3].

The sample was transferred to the laboratory and was tested.

The scope of research included:
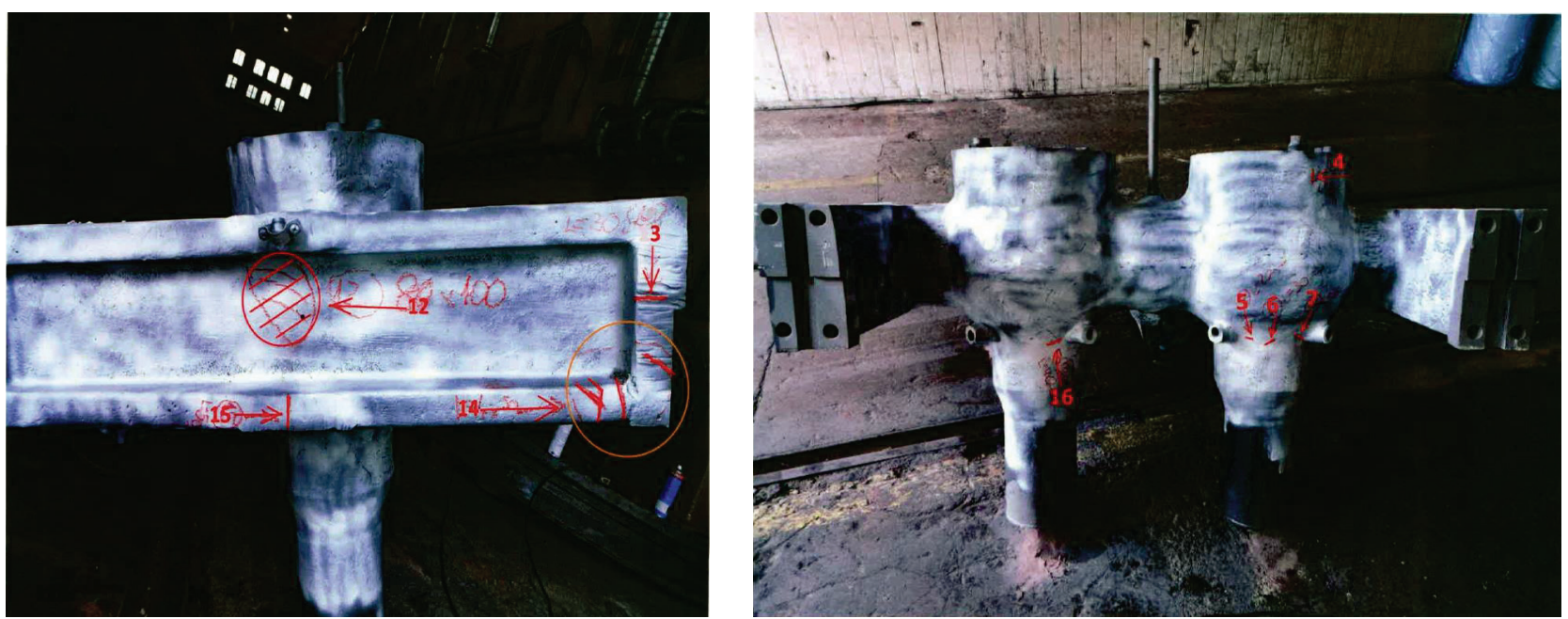

Fig. 1. Detected material discontinuities, magnetic-powder testing 


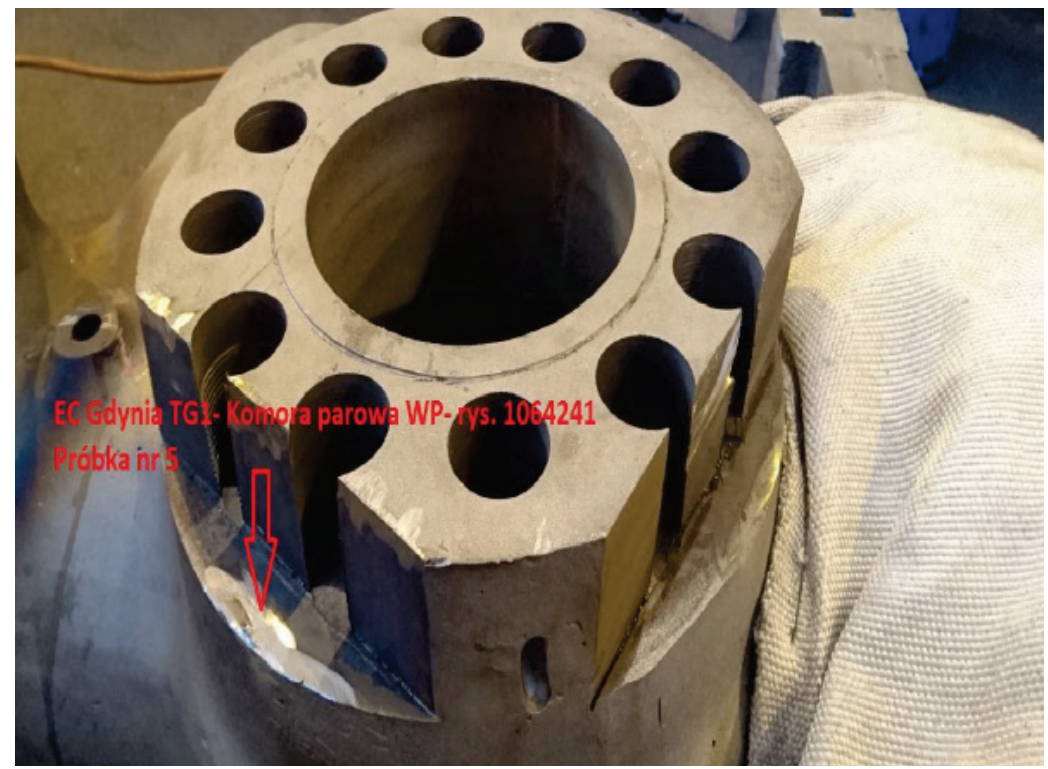

Fig. 2. Place of sample cut-out No. 5 - before revitalization

- impact test,

- hardness measurements,

- metallographic tests,

- static tensile test at ambient temperature.

The scope of test methods, equipment used and research documents are shown in Tab. 2 [3].

Tab. 2. Research methods, research equipment, standards

\begin{tabular}{|c|c|c|c|c|c|}
\hline $\begin{array}{c}\text { Standards } \\
\text { and test } \\
\text { instructions }\end{array}$ & $\begin{array}{c}\text { MT / I-101 } \\
\text { issued } 4 \\
\text { on 22-01-2016 }\end{array}$ & $\begin{array}{l}\text { PN-EN ISO } \\
6507-1: 2007\end{array}$ & $\begin{array}{l}\text { PN-EN ISO } \\
148-1: 2010\end{array}$ & $\begin{array}{c}\text { PN-EN ISO } \\
6892-1: 2010 \mathrm{~B}\end{array}$ & $\begin{array}{c}\text { MT / I-101 } \\
\text { issued } 4 \\
\text { on 22-01-2016 }\end{array}$ \\
\hline Test method & Microscopically & $\begin{array}{c}\text { Hardness } \\
\text { measurement } \\
\text { using the } \\
\text { Vickers method }\end{array}$ & Impact test & $\begin{array}{l}\text { Static tensile } \\
\text { test at ambient } \\
\text { temperature }\end{array}$ & Microscopically \\
\hline $\begin{array}{l}\text { Research } \\
\text { equipment }\end{array}$ & Axioskop & Zwick 3212 & $\begin{array}{c}\text { Charpy Zwick's } \\
\text { hammer } 5111\end{array}$ & Zwick 250 & JSM 35c \\
\hline $\begin{array}{c}\text { Test } \\
\text { conditions }\end{array}$ & $\begin{array}{l}\text { Above } \times 100, \\
\times 500, \times 1000 \\
\text { dig. } \mathrm{Mi} 1 \mathrm{Fe}\end{array}$ & Load $98.1 \mathrm{~N}$ & $\begin{array}{c}\text { Temp. } 23^{\circ} \mathrm{C} \\
\text { Karb V }\end{array}$ & $\begin{array}{l}\text { Temp. } 23^{\circ} \mathrm{C} \\
10 \times 10 \mathrm{~mm}\end{array}$ & $\begin{array}{c}\text { Above } \\
\times 100, \times 500\end{array}$ \\
\hline
\end{tabular}

\section{The results of research}

The measurements of sample hardness from the valve chamber before revitalization were made using the Vickers method and presented in Tab. 3 [3].

Tab. 3. The results of measurements of hardness $H V 10$

\begin{tabular}{|c|c|}
\hline Sample & Hardness HV 10 \\
\hline No. 5 & $145-148$ \\
\hline
\end{tabular}

The impact test and a static tensile test at ambient temperature were carried out on two samples marked 5/1 and 5/2 taken from the chamber. The results impact test and a static tensile test are presented in the Tab. 4 [3]. 
Tab. 4. The results of impact test and a static tensile test

\begin{tabular}{|c|c|c|c|c|c|c|c|c|c|c|}
\hline Sample & $\begin{array}{c}\text { The impact } \\
\text { energy of } \\
\text { Charpy V }\end{array}$ & $\begin{array}{c}\text { Dimensions } \\
\text { of the } \\
\text { sample }\end{array}$ & $\begin{array}{c}F e_{H} \\
{[\mathrm{kN}]}\end{array}$ & $\begin{array}{c}R e_{H} \\
{\left[\mathrm{~N} / \mathrm{mm}^{2}\right]}\end{array}$ & $\begin{array}{c}F_{m} \\
{[\mathrm{kN}]}\end{array}$ & $\begin{array}{c}R_{m} \\
{\left[\mathrm{~N} / \mathrm{mm}^{2}\right]}\end{array}$ & $\begin{array}{c}L_{u} \\
{[\mathrm{~mm}]}\end{array}$ & $\begin{array}{c}A_{5} \\
{[\%]}\end{array}$ & $\begin{array}{c}d_{u} \\
{[\mathrm{~mm}]}\end{array}$ & $\begin{array}{c}Z \\
{[\%]}\end{array}$ \\
\hline $5 / 1$ & $12[\mathrm{~J}]$ & $\begin{array}{c}\text { do }=10.0 \\
\text { Lo }=50\end{array}$ & 21.2 & 270 & 41.1 & 524 & 59.27 & 18.5 & 7.9 & 38 \\
\hline $5 / 2$ & $11[\mathrm{~J}]$ & $\begin{array}{c}\text { do }=10.0 \\
\text { Lo }=50\end{array}$ & 21.9 & 279 & 40.9 & 520 & 59.30 & 18.6 & 7.5 & 48 \\
\hline
\end{tabular}

The first stage of the revitalization process of the valve chamber of the steam turbine is a special heat treatment aimed at dissolving the carbides and enabling repairs with welding.

Tempering was carried out by heating to the temperature of austenite and heating at this temperature and subsequent cooling to obtain non-equilibrium structures - martensite, bainite or a mixture of martensite and bainite $[2,5]$.

The heating speed of the valve chamber was $50^{\circ} \mathrm{C} / \mathrm{h}$. The first stop is at $650^{\circ} \mathrm{C}$, after which the temperature rises again at $50^{\circ} \mathrm{C} / \mathrm{h}$ until the austenitizing temperature reaches $970^{\circ} \mathrm{C}$. The valve chamber after quenching was cooled by the blowing of air, and then it was subjected to tempering in order to reduce stresses and obtain appropriate mechanical properties, i.e. to restore the plastic deformation capacity of the material. The valve chamber has been subjected to a high tempering process to obtain the highest impact resistance with sufficient tensile strength. The heating speed was $60^{\circ} \mathrm{C} / \mathrm{h}$, until the temperature reached $690^{\circ} \mathrm{C}$, and then the chamber was cooled in air [3].

After the thermal improvement, magnetic-powder tests were carried out during which single cracks were detected. During magnetic-powder tests, the same acceptance criteria were applied as in the case of preliminary tests. The valve chamber was found and marked with defects (cracks), which were entirely qualified for removal by mechanical machining. Then, after removing the layers of material with the defects and measuring the defects, a decision was made to repair these areas by welding. After the repair of the valve chamber, mechanical and metallographic tests were carried out the same as for the scope of examination of the after-care valve chamber. The results obtained are presented in Tab. 5 [3].

Tab. 5. The results of hardness, impact energy measurements of Charpy $V$ samples and static tensile test after revitalization of the valve chamber

\begin{tabular}{|c|c|c|c|c|c|c|c|c|c|c|c|}
\hline Sample & $\begin{array}{c}\text { The impact } \\
\text { energy of } \\
\text { Charpy V }\end{array}$ & $\begin{array}{c}\text { Dimensions } \\
\text { of the } \\
\text { sample }\end{array}$ & $\begin{array}{c}F e_{H} \\
{[\mathrm{kN}]}\end{array}$ & $\begin{array}{c}R e_{H} \\
{\left[\mathrm{~N} / \mathrm{mm}^{2}\right]}\end{array}$ & $\begin{array}{c}F_{m} \\
{[\mathrm{kN}]}\end{array}$ & $\begin{array}{c}R_{m} \\
{\left[\mathrm{~N} / \mathrm{mm}^{2}\right]}\end{array}$ & $\begin{array}{c}L_{u} \\
{[\mathrm{~mm}]}\end{array}$ & $\begin{array}{c}A \\
{[\%]}\end{array}$ & $\begin{array}{c}d_{u} \\
{[\mathrm{~mm}]}\end{array}$ & $\begin{array}{c}Z \\
{[\%]}\end{array}$ & HV 10 \\
\hline $6 / 1$ & $92[\mathrm{~J}]$ & $\begin{array}{c}\text { do }=10.0 \\
\text { Lo }=50\end{array}$ & 45.2 & 576 & 54.7 & 697 & 58.29 & 18.5 & 7.2 & 48 & $\begin{array}{c}222- \\
-223\end{array}$ \\
\hline $6 / 2$ & $88[\mathrm{~J}]$ & $\begin{array}{c}\text { do }=10.0 \\
\text { Lo }=50\end{array}$ & 44.4 & 565 & 54.2 & 689 & 57.89 & 18.6 & 7.5 & 44 & $\begin{array}{c}216- \\
-217\end{array}$ \\
\hline
\end{tabular}

The repair of welding of places after selected cracks was carried out in accordance with the prepared welding instructions.

After repairs have been carried out by welding the losses of material, the valve chamber has undergone a stress relief annealing process.

The heating speed of the chamber is $57^{\circ} \mathrm{C} / \mathrm{h}$ for 9 hours, then after reaching the temperature of $725^{\circ} \mathrm{C}$ the holding time was 8 hours and then cooled down at $48^{\circ} \mathrm{C} / \mathrm{h}[3]$.

After the last heat treatment has been taken to remove the welding stresses.

Non-destructive examinations had to be carried out, the scope of which was:

- magnetic-powder tests on 100\% chamber surface, the acceptance criterion for raw (unmachined) surfaces was the same as in the case of preliminary tests, while for all areas of welding repairs it was assumed that all linear indications were not acceptable. 
During the above-mentioned non-destructive tests no unacceptable indications on the surface of the chamber were found [3].

The last step in the repair process of the valve chamber is the measurement of the hardness of the weld.

Due to the inability to take a sample for impact and microstructural tests of the weld crosssection, due to further suitability of the valve chamber for exploitation, only hardness tests were performed on the customer-selected weld marking the overall condition of the welds throughout the chamber. The results obtained are presented in Tab. 6 and place of measurement of weld hardness shown in Fig. 3.

Tab. 6. The results of weld hardness

\begin{tabular}{|c|c|c|}
\hline \multicolumn{3}{|c|}{ Hardness HV5 } \\
\hline Material & HAZ & weld \\
\hline $196-204$ & $216-236$ & $196-205$ \\
\hline
\end{tabular}

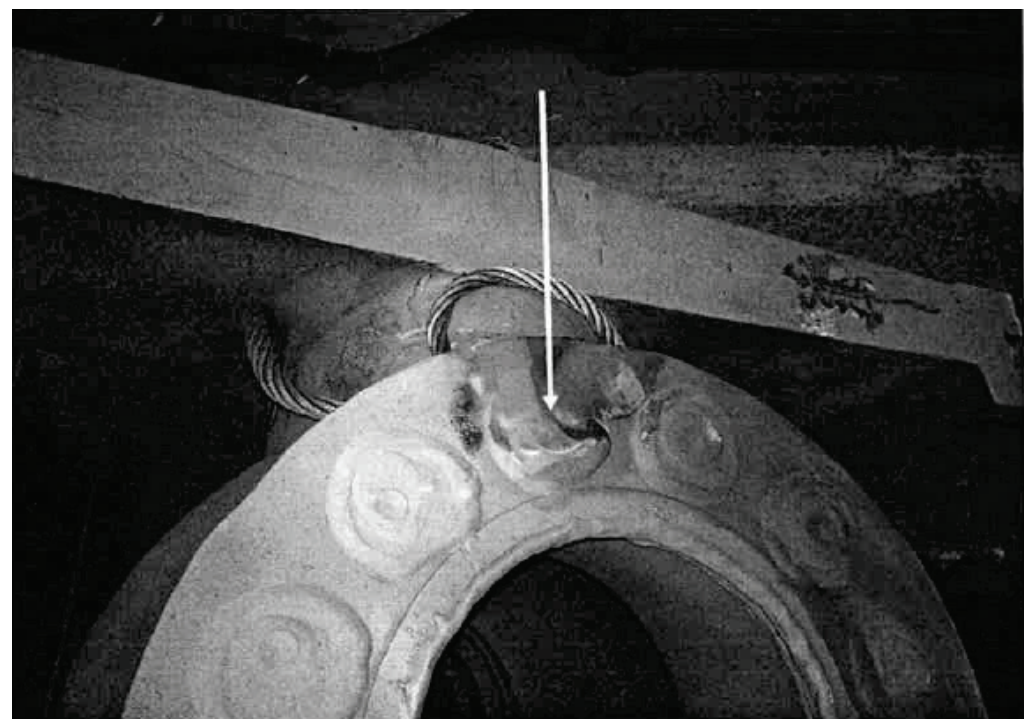

Fig. 3. Place of measurement of weld hardness

\section{Summary and conclusions}

The microstructure of the valve chamber material after regeneration is composed of tempered bainite. The microstructure of tempered bainite, from the metallological point of view, is a microstructure more favorable than the L21HMF (ferrite-perlitic) ferrite casting produced at the production stage. The impact strength of the chamber material after revitalization is very high. The work of breaking, tested on Charpy samples by notching V, ranges from $88 \mathrm{~J}$ to $92 \mathrm{~J}$. Strength properties $\left(R_{m}, R_{p 0.2}, Z\right)$ of the valve chamber are high after revitalization. The repair of welds after selected cracks was carried out correctly, which confirms the hardness distribution on randomly selected repair joints. The valve chamber may still be used after previous revitalization as a new chamber.

\section{References}

[1] Dobosiewicz, J., Influence of exploitation on changes of mechanical properties of metal of steam turbine hulls, Energetyka, 1, p. 27, 1992.

[2] Cicholska, M., Czechowski, M., Ship material science, publishing of the Maritime University of Gdynia, Gdynia 2013. 
[3] Expertise of repairs, EC Gdynia TG1.

[4] Rajca, S., Grzesiczek, E., Condition of the material of the steam turbine hull after repair by welding, Energetyka, 12, s. 777, 2001.

[5] Rehmus-Forc, A., Structural changes occurring after the revitalization of steam turbine hulls, Materials Engineering, No. 3, pp. 265-267, 2006.

[6] Trzeszczyński, J., Grzesiczek, E., Replace or revitalize?, Energetyka, 7, 1998.

Manuscript received 15 July 2019; approved for printing 03 September 2019 